VI.

\title{
Case of Eclampsia Treated by the Administration of Chloroform in the Year 1849,
}

\author{
By John Rimington Fothergill, M.D., Darlington.
}

Mrs. P., of Darlington, a stout, healthy woman, was pregnant of her first child, and was first seen by my father, John Fothergill, M.R.C.S., some months before the full time. She was recommended to pay attention to her bowels during the remainder of her pregnancy, but this she appears to have neglected.

Symptoms of labour occurred on a Saturday evening late in the year 1849. She was seen early the next morning and was then having pains; but the labour was not sufficiently far advanced to demand the continued attention of the practitioner. At about eleven o'clock he was sent for in haste and found her in a strong eclamptic fit. She was then bled from the arm to from 20 to 22 ounces. The os nteri was well dilated and the head had descended low in the pelvis, though not so far as to reach the perineum. The membranes had ruptured the day before. She was extremely restless and unmanageable, and bounced from one side of the bed to the other whenever an examination was attempted. My father then made use of chloroform. The patient was soon perfectly quiet, the pains all the while continuing extremely efficient. By the time the state of the case would have admitted of the application of the forceps, it was evident that this would not be necessary and the patient was speedily delivered of a fine, healthy boy. But unhappily the eclamptic fits soon returned and continued violently during the whole of the night. On the following day the fits were much abated in duration and frequency, as well as in strength, but the pulse was very rapid, small and irregular, sometimes being almost imperceptible. Sinapisms were applied to the calves of the legs and a long blister to the spine. The hair was removed from the head and cold water was freely applied. Calomel was exhibited in one dose, with croton oil. Enemata, containing turpentine, oil and assafœetida, were also given. The eatheter was several times introduced, a considerable quantity of urine being drawn off each time. During the next night the patient had no return of the fits, and in the morning was much more conscious. She recognized some of her friends, and was able to swallow. She did not appear to know that she was delivered, for 
on hearing the child cry downstairs she seemed surprised. It was brought upstairs and applied to the breast. From this time she continued to improve and made as perfect a recovery as if no untoward symptom had appeared.

The above notes I have recently found amongst some old papers. I originally wrote them out for communication to an Edinburgh Students' Medical Society, which was known as the "Hunterian," and of which I was once President-it must have been in the year 1850. As an Edinburgh student of that time, I was familiar with chloroform, and I remember discussing its uses with my father during the vacation in the year 1849. Shortly after my return to my studies in Edinburgh this case of eclampsia occurred, in which the convulsions were controlled and delivery was completed under chloroform anæsthesia, as my father informed me by letter at the time. I think it must be one of the earliest cases in which chloroform was used for this purpose. 